\title{
La anticoncepción poscoital de emergencia con levonorgestrel fue más efectiva y mejor tolerada que el régimen combinado
}

Randomized controlled trial of levonorgestrel versus the Yuzpe regimen of combined oral contraceptives for emergency contraception. Task Force on Postovulatory Methods of Fertility Regulation: Word Health Organization. The Lancet.1998; 352: 428-433.

\section{Objetivo}

Comparar dos métodos de anticoncepción de emergencia post-coito para evaluar su eficacia y efectos adversos.

\section{Diseño}

Ensayo clínico randomizado doble ciego.

\section{Lugar}

Estudio multicéntrico, realizado en 21 centros de 14 países.

\section{Pacientes}

Participaron 1998 mujeres sanas, con ciclos menstruales regulares, que no usaban un método de anticoncepción hormonal y consultaron por anticoncepción postcoital dentro de las 72 horas de haber tenido un coito sin protección.

\section{Intervención}

Se randomizó a las pacientes para recibir $0,75 \mathrm{mg}$ de levonorgestrel cada doce horas o el régimen de Yuzpe $(100 \mu \mathrm{g}$ de etinilestradiol más $0,75 \mathrm{mg}$ de levonorgestrel cada doce horas).

Se les indicó registrar el patrón menstrual y si presentaban efectos adversos durante la semana siguiente de administrada la medicación.

\section{Medición de resultados principales}

El resultado principal fue embarazo, se midió en números crudos y en tasa de reducción de embarazos estimados o fracción de embarazos

\section{prevenida.}

Secundariamente se evaluaron los efectos adversos y cambios en el patrón menstrual.

\section{Resultados principales}

Se perdieron del seguimiento 43 pacientes $(2,2 \%) ; 25$ asignadas al grupo levonorgestrel y 18 al régimen Yuzpe. De las 1955 mujeres que se obtuvieron resultados, la tasa cruda de embarazo fue del $1,1 \%$ (11/976) en el grupo de levonorgestrel y del 3,2\% (31/979) del grupo con el régimen Yuzpe. Esto implica un riesgo relativo (RR) crudo de embarazo con levonorgestrel comparado con el régimen Yuzpe de 0,36 (IC 95\% 0,18-0,70).

La proporción de embarazos prevenidos (comparado con el número esperado de embarazos sin tratamiento) fue $85 \%$ para el grupo que recibió levonorgestrel y $57 \%$ para el otro grupo.

En cuanto a los efectos adversos, las náuseas y vómitos fueron menos frecuentes en el grupo levonorgestrel, $23,1 \%$ vs. $50,5 \%$ y $5,6 \%$ vs. $18,8 \%$ respectivamente.

\section{Conclusión}

El régimen con levonorgestrel para anticoncepción postcoito fue mejor tolerado y más efectivo que el régimen combinado habitualmente utilizado. La eficacia de ambos tratamientos disminuye a medida que aumenta el tiempo en la administración del tratamiento.

\section{COMENTARIO}

La anticoncepción poscoital es una estrategia terapéutica para disminuir la tasa de embarazos no deseados, inhibiendo o retrasando la ovulación y previniendo la implantación. En EE.UU. alrededor de 50 millones de embarazos son interrumpidos cada año, y se estima que cerca de 1 millón de abortos y 2 millones de èmbarazos no deseados podrían evitarse con anticoncepción poscoital ${ }^{1}$. Existen en la actualidad diferentes métodos hormonales: altas dosis de estrógenos, estrógenos y progestágenos combinados, danazol, antiprogestágenos (mifepristona), y progestágenos solos. Esta última opción ya se estudió previamente en un ensayo clínico en 1993, donde 0,75mg de levonorgestrel cada doce horas tuvo una tasa de eficacia similar a los anticonceptivos combinados (2,6\% anticonceptivos combinados vs. $2,4 \%$ progestágeno solo) y hubo una tendencia a la disminución de los efectos adversos ${ }^{2}$. La Organización Mundial de la Salud llevó a cabo este estudio multicéntrico comparando el régimen progestágeno solo y el combinado, a través del cual se demuestra que es de mayor eficacia y confirma el menor número de efectos adversos. El trabajo está bien diseñado $y$, con estos resultados, consideramos que este régimen debería convertirse en el de elección para contracepción postcoital.

Con la diferencia en la tasa de embarazos observada en este estudio, por cada 50 mujeres tratadas con levonorgestrel se prevendría un embarazo más que con el régimen combinado. En nuestra práctica diaria debemos educar a los pacientes en cuanto a los métodos anticonceptivos existentes, que la pareja elija el que considera más apropiado y nunca olvidar de reforzar medidas de prevención de enfermedades de transmisión sexual. Un tema controvertido es cuánto deben saber de la existencia de estos métodos ${ }^{3}$, o cómo evitar que las pacientes escojan estos métodos como de primera línea. No obstante es claro que deben conocer que está la posibilidad de prevenir un embarazo y que deben consultar lo más rápido posible al médico luego de haber sufrido un "accidente" 4 .

Dra. Vilda Discacciati

Unidad de Medicina Familiar y Preventiva. Hospital Italiano Buenos Aires. 